\title{
Grey Gold: Do Older In-Migrants Benefit Rural Communities?
}

\author{
BY NINA GLASGOW AND DAVID L. BROWN
}

\section{The Importance of Understanding Retirement Migration}

$\mathrm{M}$ igration often accompanies life course transitions, including retirement. While young people are much more likely than older adults to move, almost 10 percent of Americans aged 60+ migrated between counties during 1995 to 2000, with a disproportionate share moving to rural communities. In fact, 274 nonmetropolitan counties experienced net in-migration rates of 15 percent or higher among persons ages $60+$ during this period. The United States Department of Agriculture designated those counties as rural retirement destinations (RRD), and we use this categorization in our research as well. ${ }^{1}$ As might be expected, most RRDs are located in the South and West, but over one quarter (75 of 274) are in the Midwest (RRDs are designated in black or grey in Figure 1). Rural retirement destinations are also found in scattered areas of the Northeast.

Population aging is a dramatic and widespread demographic phenomenon in the U.S. today. About 12 percent of Americans and almost 15 percent of those residing in rural counties are presently ages $65+$, and this share will increase to about 20 percent when the Baby Boom enters retirement age. If new cohorts of older persons maintain the migration behavior of current retirees, older in-migration to rural areas will persist into the future. There seems little question that this will be the case, given the fact that nonmetropolitan areas have experienced net in-migration at ages $60+$ during three of the last five decades, with the rate of in-migration at these ages being particularly high during the rural growth decades of the 1970s and 1990s (Figure 2). In fact, rural retirement destinations are one of the only types of nonmetropolitan counties to experience consistent population growth during the last 30 years. Older in-migration to nonmetropolitan places has an effect on destination communities that extends well beyond its impact on overall population growth. Because older in-migration affects age composition, it indirectly shapes community needs and demands for goods, services and economic opportunities, as well as patterns of consumption, lifestyles and social relationships.

Moving at relatively older ages has important implications for migrants themselves and for the places in which they settle. Accordingly, our research examines both micro- and macro- aspects of rural retirement migration. It provides an empirically-based assessment of factors associated with the development of rural retirement destinations and of community-level impacts linked with attracting older in-migrants. At the micro-level, we examine the social and economic dynamics of older in-migration, the process by which older in-migrants establish social relationships in their new communities, and the impacts of their social integration (or lack thereof) for their health and well being.

\section{How We Conducted Our Study}

We used a multi-method approach to examine the micro and macro aspects of retirement in-migration. We conducted a two wave panel survey in 2002 and in 2005 to examine how older in-migrants become socially integrated in rural destination communities. Our survey was administered in 14 purposely selected RRDs spread across the country (shown in black in Figure 1). ${ }^{2}$ We collected data from matched samples of in-migrants who were ages $60+$ and longer term residents who were in the same age group. Our survey included 788 respondents at wave 1 and 603 respondents at wave 2. Minus the amount of attrition that occurred between wave 1 conducted in 2002 and wave 2 conducted in 2005, we interviewed the same individuals at both points in time. An approximately equal number of in-migrants and longer-term older resident respondents were interviewed in each county. The survey included a battery of questions 
Figure 1: Rural Retirement Destination Counties, Including Survey and Case Study Counties

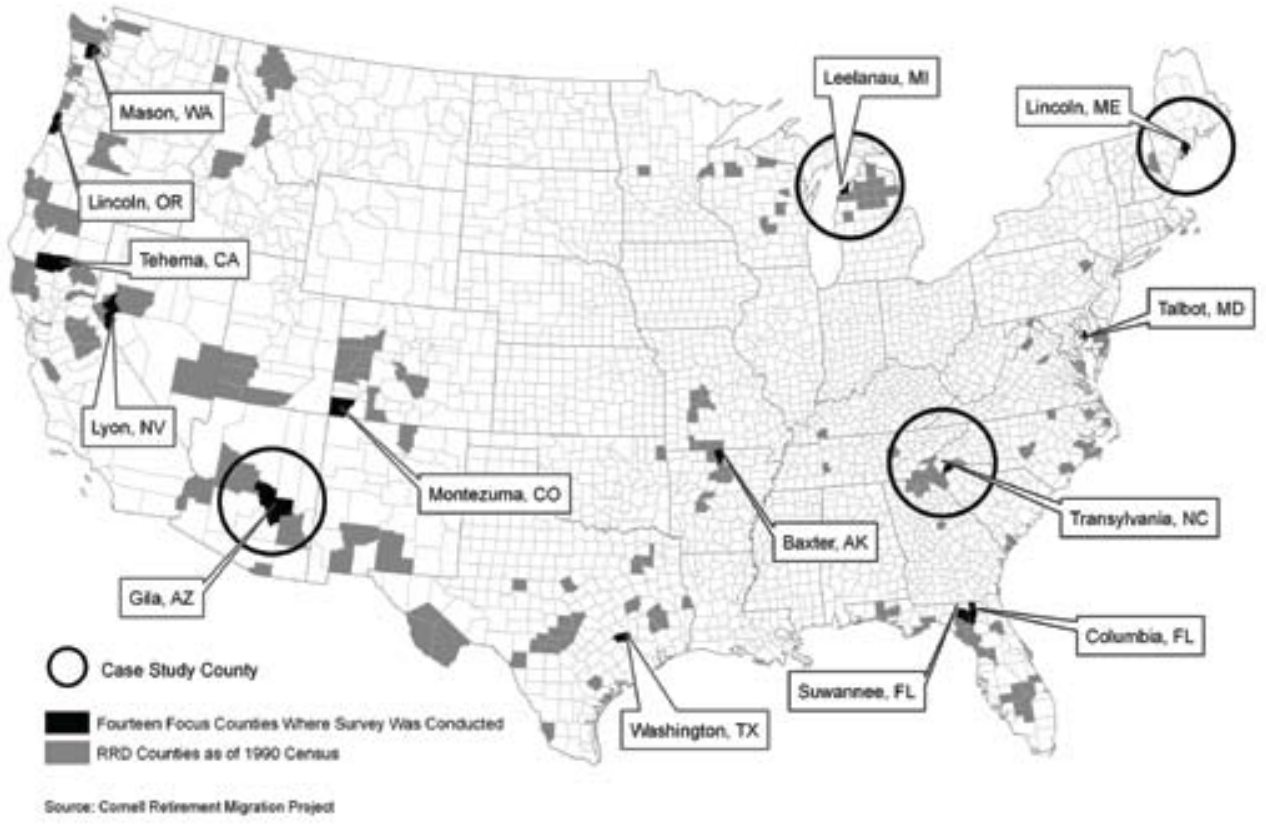

about respondents' social relationships, organizational participation, migration experience, health, and socioeconomic and demographic status. We used both county-level census data and in-depth case studies to provide a macro-level context for our survey research. In our larger study, we used Census data to profile RRDs, to compare them with other types of nonmetropolitan areas, and to investigate why some counties are more likely to become and remain RRDs than others. Case studies in four selected survey RRDs (circled in Figure 1), one in each region of the country, were conducted to examine how older in-migration was affecting destination communities. ${ }^{3}$ We spent approximately one week in each county and interviewed more than 60 public officials, business owners, service providers and organizational leaders while also conducting face-to-face interviews with 6-7 older in-migrants in each community who had previously responded to both waves of our survey. The three data sources provided complimentary information that illuminated questions examined in our study.

\section{Older In-Migrants and Their Rural Destination Communities}

In this brief we focus on one of the micro-level questions and one of the macro-level questions that motivated our study. ${ }^{4}$ At the micro level, we examine older in-migrants' patterns of social integration in their new communities. At the macro-level we consider the community-level impacts of older in-migration.

\section{Are older in-migrants socially isolated in destination rural communities?}

Our panel survey of older in-migrants was motivated by a concern that persons who change residences later in life might have difficulty establishing social relationships and becoming socially integrated in their new communities. Our research demonstrates that our concerns about social isolation among older in-migrants were unfounded. Our survey showed that older in-migrants quickly became involved in their new communities. In fact, their levels of

\section{Figure 2: Non-MEtropolitan Age-SPECific Net Migration Rates, 1950-1990}

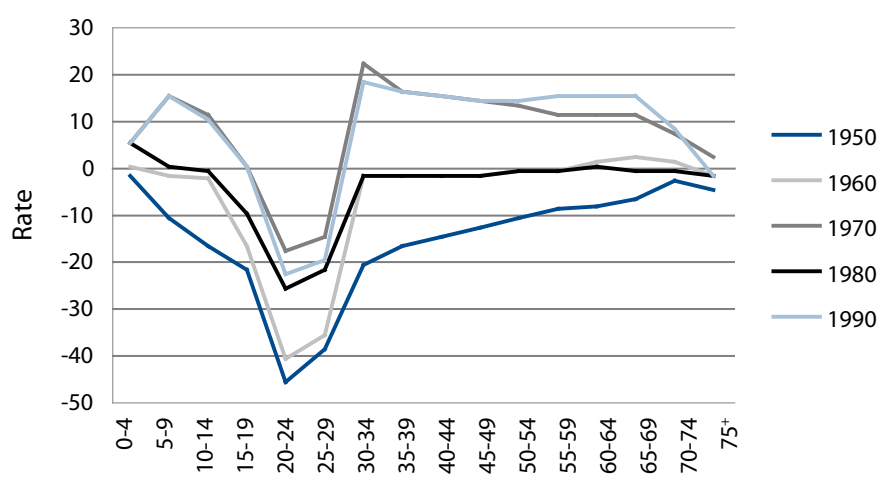

Source: Kenneth M. Johnson and John B. Cromartie. 2006. "The Rural Rebound and Its Aftermath." Pp. 25-50 in W. Kandel and D. Brown (Eds.) Population Change and Rural Society. Dordrecht: Springer. 
Figure 3. Availability to Elders of Kin in Rural Retirement Destinations, 2005

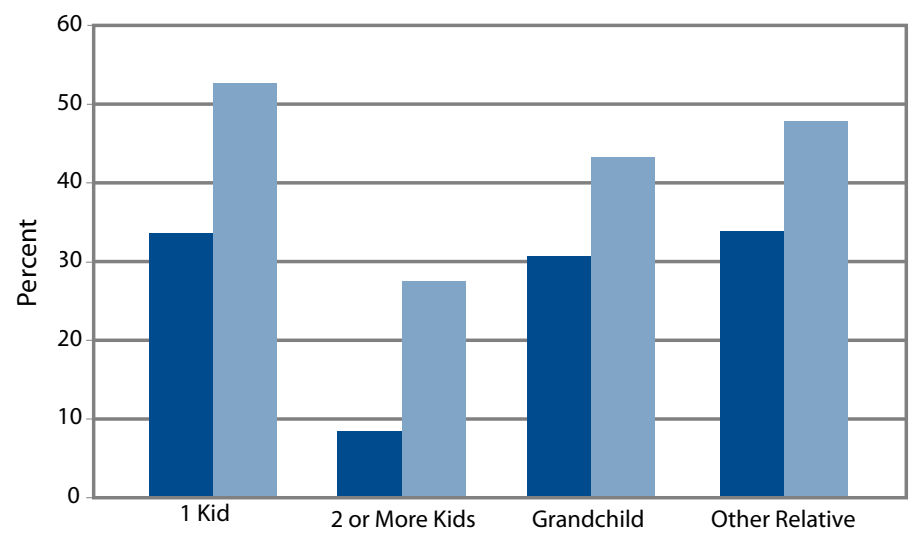

2005 Migrants

2005 Non-migrants

Figure 4. Formal Social Participation of Migrants and Non-Migrants in Retirement Destinations, 2005

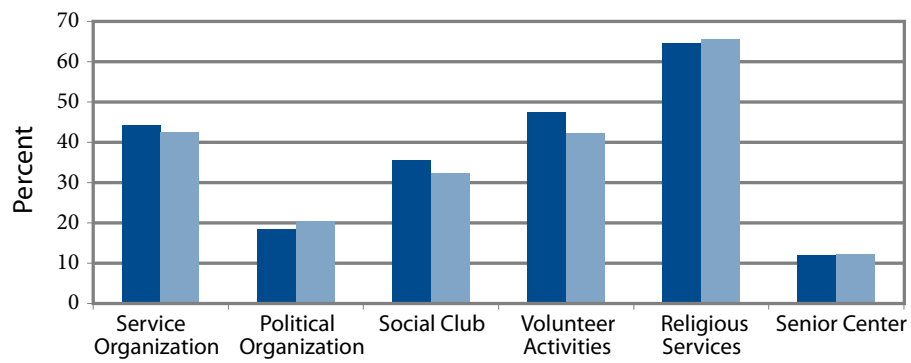

2005 Migrant

2005 Non-Migrant

social integration closely matched those of similarly aged persons who had lived in RRDs for over 20 years. In-movers have similar levels of social involvement in both primary and secondary realms. We found that over one-third of older in-migrants had at least one adult child living within a one-half hour drive of their new home, while almost 50 percent of longer-term older residents did (Figure 3). Moreover, older in-migrants and non-migrants visited friends and neighbors 1-2 times per week with equal frequency. In 2002 when the in-migrants had lived in an RRD 5 or fewer years, 58.5 percent of in-migrants were involved in at least one local organization, and, across different types, in-migrants were almost as likely as longer-term residents to participate in organizations (data not shown). By the second wave of our survey conducted in 2005, in-migrants were more likely than longer-term older residents to participate in service, social, and volunteer activities (Figure 4). Older in-movers are active in a wide range of social, civic, religious, and service organizations, and they are especially likely to volunteer. Community leaders we interviewed reported that through their labor, technical expertise, and financial contributions, older in-movers are a driving force in community activities and organizations.

\section{What are the community-level costs and benefits associated with older in-migration?}

Previous research tended to concentrate on the economic impacts of older in-migration; few studies have considered the social impacts. Our interviews with local leaders in four destination communities focused on the social opportunities and challenges associated with attracting retirement age migrants to their communities. Our interviewees told us that in-migration of retirees has a positive impact on the real estate market and on construction; in-migrants provide financial and technical assistance to a wide array of civic endeavors; and they invigorate the arts and cultural scene.

Some benefits associated with older in-migration were also associated with costs. Hence whether older in-migration was viewed as positive or negative depended upon one's place in the community. Rising real estate prices, for example, reduced the supply of affordable housing, especially for teachers, health care workers, first responders, and young families. Volunteering reduces public-sector costs, but it may also diminish the demand for paid professional workers, thereby undermining a community's ability to retain its better trained youth. Older in-migrants who take positions of cultural leadership were reported by community leaders to sometimes be insensitive to traditional ways of doing things and to try to impose their tastes and preferences on the community. Older in-migrants often become politically active, and we found examples of older newcomers competing for power with the more established leadership.

The fact that over 30 percent of older in-migrants have adult children residing nearby also had positive implications because adult children can provide care giving to their parents as the parents age-in-place in destination communities. Contrary to the developmental theory of older migration ${ }^{5}$, which predicts that older in-migrants will leave amenity rich RRDs as they advance in age; become ill or disabled; lose their spouse; and/or have to relinquish their driver's license, we believe those with adult children living nearby are unlikely to move away. Thus we believe some portion of older in-migrants will remain in the RRD after their contributions to the community diminish in relation to their costs. We verified that 35 respondents (approximately half of whom were in our in-migrant sample and 
half in the longer-term resident sample) moved from a study county between 2002 and 2005, but only three years had elapsed between wave 1 and wave 2 of our panel survey. To make more definitive statements about who will move from or remain in RRDs, additional waves of data collection are needed.

\section{How RRDS Can Maximize Opportunities and Minimize Costs Associated With Older In-Migration}

What can rural destination communities do to maximize the opportunities and reduce the costs associated with older in-migration? Older in-migration should not be seen as a "pensions and care issue" or as a panacea for strapped rural economies, but rather as a source of both challenges and opportunities. With thoughtful planning older in-migration can be a significant asset to rural community development. Specifically, we recommend the following:

- Communities should promote an inclusive environment that encourages high levels of social participation among older residents. Not only will this contribute to productive aging among the older in-migrants themselves, it will also strengthen local institutions by supplying volunteer labor and other types of support.

- Community decision-making processes should be open and inclusive so that all voices are heard when the public agenda is established and when policy actions are taken. Older in-migrants can be a benefit to their new communities, but they can also displace longer-term residents. In-migrants' needs and opinions cannot be privileged above those of longer-term residents.

- Community planning must address both shorter- and longer-term concerns. Older in-migrants tend to have few immediate needs, but they may require public transportation, health care, and other forms of assistance in the future.

- As the mid-twentieth-century Baby Boom cohorts begin to enter older age, growing waves of older in-migrants will join previous in-migrants in rural retirement destinations. As a result, the older population of such areas will reflect a more diverse age composition. This will generate a complex mix of costs and benefits relevant to planning for future community needs. The "grey gold" that older in-migration represents in the perceptions of some public officials and community leaders in RRDs needs to be considered from a balanced perspective.

\section{Authors}

Nina GLASGOW is a senior research associate in the Department of Development Sociology at Cornell. Her career has been based on addressing a wide range of issues concerning aging in rural communities.

DAVID BROWN is a professor of development sociology at Cornell University where he also directs the Community and Rural Development Institute and the Cornell Population Program.

\section{Endnotes}

1 Counties were classified as rural retirement destinations by USDA's Economic Research Service, if they had 15 percent or higher net migration at ages 60 and above between 1995 and 2000. In our research, we focused on "naturally occurring" retirement communities as opposed to age segregated, comprehensively planned retirement communities, such as Sun City, Arizona.

2 Our first wave was administered before USDA released the list of RRDs based on the 2000 census. Accordingly, we selected our survey counties from the list of 190 RRDs based on the 1990 census. If we had selected our survey sites randomly, most of them would have been in the Southeast and Southwest. But we wanted to examine older in-migration in the diversity of contexts where it occurs in the US.

3 These case studies were conducted in Lincoln County, Maine, Transylvania County, North Carolina, Gila County, Arizona, and Leelanau County, Michigan.

4 While we cannot review all, or even most, of our findings in this research brief, a full report of the study is available in our new book, Rural Retirement Migration, Springer (2008).

5 The developmental theory of older migration was proposed by Litwak and Longino (The Gerontologist, Vol. 27, no.3, 1987)

\section{CARSEY}

Building knowledge for families and communities

The Carsey Institute at the University of New Hampshire is a leading center for policy research on vulnerable children, youth, and families and sustainable community development.

We give policy makers and practitioners timely, independent resources to effect change in their communities.

Huddleston Hall

73 Main Street

Durham, NH 03824

(603) $862-2821$

www.carseyinstitute.unh.edu 